\title{
Research beyond biomedical confines: towards better mental health and well-being for all
}

Jou Yin Teoh ${ }^{1, *}$ and Kee Hean Lim $^{1}$

${ }^{1}$ Division of Occupational Therapy, Department of Clinical Sciences, College of Health and Life Sciences, Brunel University London, United Kingdom.

* Correspondence: jouyin.teoh@brunel.ac.uk

Published: 19 November 2019

https://doi.org/10.31117/neuroscirn.v2i4.43

Keywords: mental health; mental disorder; suicide prevention; mixed-methods research; collaborative research;

C2019 by Teoh and Lim for use and distribution in accord with the Creative Commons Attribution (CC BY-NC 4.0) license (https://creativecommons.org/licenses/by-nc/4.0/), which permits unrestricted non-commercial use, distribution, and reproduction in any medium, provided the original author and source are credited.

'Working Together to Prevent Suicide' is the theme of World Mental Health Day 2019. According to the World Health Organisation [1] , suicide is the second leading cause of death for people aged 15-19 years old. One person dies of suicide every 40 seconds, with this form of death affecting people of all age groups in all countries. Hence in line with this year's theme calling for a trans-sectoral and interdisciplinary approach to address this epidemic, we would like to invite all contributors and readers of Neuroscience Research Notes (NeurosciRN) to take a moment to reflect on how they - as researchers can contribute towards the facilitation, discussion and promotion of positive mental health, which in turn has been found to reduce suicide risk $[\underline{2}, \underline{3}]$.

The link between suicide and mental disorders is well established, to the point where concerns have been raised that the extent to which mental disorders contribute to suicide could have been overinflated. Individuals with a mental disorder have a nearly eightfold increased risk of suicide compared with those without a mental disorder; hence, the risk these conditions present should not be downplayed [4]. Nonetheless, our review of NeurosciRN publications over the past two years has found only three articles to date, which focused specifically on mental disorders, namely dementia [ㄷ], bipolar disorder []], and major depressive disorder [] . Thus, it may not be a surprise for the majority of both researchers and the readership to question when confronted with this editorial: 'Why should I be concerned about considering the aspect of mental health to address suicide risk and if so how could I then contribute towards suicide prevention through research, discussion and promotion of mental health and well-being?'

As a starting point, we feel it is important to clarify differences between mental disorders and mental health (also known as psychological health). A person with a serious mental disorder can enjoy good mental health with appropriate management of their condition and a supportive social environment; likewise someone experiencing chaotic life circumstances can be in poor mental health even without a psychiatric diagnosis []. Direct links have been established between physical and 
mental health. The state of one's mental health can influence decisions and behaviours around diet, exercise, alcohol consumption, with poor mental health, subsequently curtailing the promotion of physical health $[\underline{9}, \underline{10}]$. Furthermore, seminal work around the neurobiological effects of psychological trauma [11] and developments in the field of cultural neuroscience $[\underline{12}, \underline{13}]$ have provided insight to how circumstances in the external social environment can impact upon mental health and psychological wellbeing and physically influence brain development and genetics [11 $\underline{13}$ ]. Despite these findings, mental and physical health remain separate entities in most systems of healthcare service and delivery and are managed apart from each other. This neglect of the interconnectedness between both can easily harm patients, as it is not uncommon for many to require attention for a complex combination of physical and mental health needs.

The presence of physical disabilities, for example, can lead to poor mental health as a result of social factors such as disability-related discrimination and heighten risk for the development of mental disorders such as depression, anxiety and post-traumatic stress disorder [14]. Our review of past articles indicated that contributors to NeurosciRN are keen to understand and develop interventions for a wide variety of health conditions closely associated with functional disability

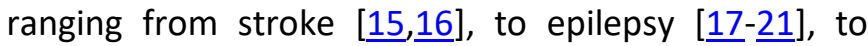
neurodegenerative diseases [22] as well as Down's syndrome [23-25]. 'Functional disability' refers to how people with health conditions are prevented from engaging and participating in activities, roles and other aspects of their lives, which are of value to them. The pervasive impact of disabilities on daily life can easily result in decreased life satisfaction and adverse effects on mental health and well-being, as well as elevated suicide risk $[\underline{14}, \underline{26}, \underline{27}]$. These highly complex and disabling interactions between health conditions and the psychosocial and contextual dimensions in which they occur are impossible to capture within the purely biomedical research paradigm dominant among articles in NeurosciRN.
These limitations are acknowledged in the latest Medical Research Council guidelines for Developing and Evaluating Complex Interventions [28] which includes calls for research on health conditions to move away from lab-based experimental methods as the best or only option, as well as to incorporate more qualitative, user-involved methods for a more thorough examination of engagement and outcomes. In the treatment of pain, for example, neuroscientists would be primarily concerned with identifying parts of the brain affected by pain or developing pharmaceutical interventions that engage with one's biology for purposes of pain reduction. What is missing from such research, though, is the examination of societal impact. What benefits are there in developing pharmaceutical drugs with high efficacy? How do such drugs influence the effects of pain on an individual's relationship with the people around them, as well as their engagement and participation with activities, roles and other life priorities that become side-lined as a result of their condition? If the person in pain were to face precarious employment and finances, how would that affect their access to the drugs needed to keep their debilitating condition at bay - and what would the consequences be on the various aspects of their lives? Existing research shows that suicidal behaviours or completion of suicide are at least twice as likely to occur in individuals with chronic pain; that chronic pain and its potential consequences of unemployment and disability are all significant risk factors for suicidality [29]. We argue that biomedical research conducted without engagement with the psychological, emotional and social dimensions of lived experiences of the populations the research is meant for is incomplete and its potential for impact curtailed.

Thus, our challenge to you as neuroscience researchers is for you to contribute towards the bigger picture of the promotion of mental health and well-being, as well as suicide prevention by reaching out beyond the confines of the biomedical paradigm to build collaborative partnerships which can instil a more holistic perspective of health and well-being into your work, if you are not already doing so. Contemplate mixed methods or 
approaches within your research and consider how you can work with fellow researchers using phenomenological, ethnographic, and other qualitative approaches to explore and discover the realities and respond to the personal lived experiences of those you research. Perhaps even look into how the people you research and other relevant stakeholders can be included in deciding on the focus and even types of inquiry undertaken. The promotion of mental health can be, and should be everyone's business. What can you do to make it yours too?
Conflicts of Interest: The authors declare no conflict of interest.

Author Contributions: Both authors provided an equal contribution to the manuscript.

Acknowledgements: J.Y.T is grateful for the invaluable conversations with Drs Kei Long Cheung, Dido Green, Jo Howe, Debbie Long, and Academic Social Media, which helped shape and clarify her work for this article.

\section{References}

1. WHO.int. Available online: https://www.who.int/docs/default-source/mental-health/suicide/flyer-40secondsweb.pdf?sfvrsn=5ba643c 2 (accessed on 30 September 2019)

2. Teismann T, Forkmann T, Brailovskaia J, Siegmann P, Glaesmer H, Margraf J. Positive mental health moderates the association between depression and suicide ideation: A longitudinal study. Int J Clin Health Psychol. 2018;18(1):1-7. https://doi.org/10.1016/j.ijchp.2017.08.001

3. Siegmann P, Teismann T, Fritsch N, Forkmann T, Glaesmer H, Zhang XC, et al. Resilience to suicide ideation: A crosscultural test of the buffering hypothesis. Clin Psychol Psychother. 2018;25(1):e1-e9. https://doi.org/10.1002/cpp.2118

4. Too LS, Spittal MJ, Bugeja L, Reifels L, Butterworth P, Pirkis J. The association between mental disorders and suicide: $\mathrm{A}$ systematic review and meta-analysis of record linkage studies. J Affect Disord. 2019;259(08):302-313.

https://doi.org/10.1016/i.jad.2019.08.054

5. Azam NF, Stanyard RA, Mat NH, Hassan Z. Cholinergic modulation of hippocampal long-term potentiation in chronic cerebral hypoperfused rats. Neurosci Res Notes. 2018;1(1):42-57. https://doi.org/10.31117/neuroscirn.v1i1.15

6. Zain MA, Zainal NZ, Kanagasundram S, Mohamed Z. Genetic association study of PDLIM5 and HTR2A variants in Malaysian subjects diagnosed with bipolar disorder; a genetic modelling approach. Neurosci Res Notes. 2018;1(1):11-20. https://doi.org/10.31117/neuroscirn.v1i1.9

7. Lye MS, Tey YY, Tor YS, Ling KH, Ibrahim N, Stanslas J, et al. Zinc transporter-3 [SLC30A3 (rs11126936)] polymorphism is associated with major depressive disorder in Asian subjects. Neurosci Res Notes. 2019;2(3):20-28. https://doi.org/10.31117/neuroscirn.v2i3.34

8. Benton S. The Difference Between Mental Health and Mental Illness. It might not be what you think. Psychology Today. Posted on April 12, 2018. Available online: https://www.psychologytoday.com/us/blog/reaching-across-thedivide/201804/the-difference-between-mental-health-and-mental-illness (accessed on 30 September 2019)

9. Ohrnberger J, Fichera E, Sutton M. The relationship between physical and mental health: A mediation analysis. Soc Sci Med. 2017;195(1):42-49. https://doi.org/10.1016/i.socscimed.2017.11.008

10. Mental Health Foundation. Fundamental Facts about Mental Health 2016. Mental Health Foundation: London, 2016; Available online: https://www.mentalhealth.org.uk/sites/default/files/fundamental-facts-about-mental-health-2016.pdf

11. Van der Kolk B. The body keeps the score: Brain, mind, and body in the healing of trauma. Viking Penguin: New York, USA, 2014; ISBN 978-1-101-60830-2.

12. Han S. The Sociocultural Brain. Oxford University Press: New York, USA, 2017; ISBN 978-0-19-874319-42017. https://doi.org/10.1093/acprof:oso/9780198743194.001.0001

13. Chiao JY, Li SC, Seligman R, Turner R. The Oxford handbook of cultural neuroscience. Oxford University Press: New York, USA, 2016; ISBN 978-0-19-935737-6. 
14. Khazem LR. Physical disability and suicide: recent advancements in understanding and future directions for consideration. Curr Opin Psychol. 2018;22(07):18-22. https://doi.org/10.1016/i.copsyc.2017.07.018

15. Huang S, Lin M, Pan X, Tan Q, Tan K-L. The potential of MLC901 (NeuroAiD II ${ }^{\mathrm{TM}}$ ), a traditional Chinese medicine. Neurosci Res Notes. 2019;2(2):18-24. https://doi.org/10.31117/neuroscirn.v2i2.32

16. Toh TH, Idris I, Ahmad SB, Lim TT, Looi I, Chan CK, et al. Genotypic and phenotypic variation of CADASIL among Chinese, Indians and Rungus in Malaysia. Neurosci Res Notes. 2019;2(3):1-11. https://doi.org/10.31117/neuroscirn.v2i3.35

17. Jaafar A, Alsiddiq F, Ling KH. Pathogenic mutations in ARX, CDKL5 and STXBP1 genes are not associated with the earlyonset epileptic encephalopathy in Malaysian pediatric patients: A pilot study. Neurosci Res Notes. 2018;1(3):5-17. https://doi.org/10.31117/neuroscirn.v1i3.16

18. Then S-M, Raymond AA. An update on HLA alleles as pharmacogenetic markers for antiepileptic drug-induced cutaneous adverse reaction. Neurosci Res Notes. 2019;2(2):1-17. https://doi.org/10.31117/neuroscirn.v2i2.29

19. Choo BKM, Kumari Y, Hue SM, Shaikh MF. The treatment of epileptic seizures: the potential of Malaysian medicinal plants. Neurosci Res Notes. 2019;1(3):35-53. https://doi.org/10.31117/neuroscirn.v1i3.27

20. Leo A, De Caro C, Nesci V, Tallarico M, Mangano G, Palma E, et al. WAG/Rij rat model: a resource for the pharmacology of epileptogenesis and related neurological/psychiatric comorbidities. Neurosci Res Notes. 2019;1(3):18-34. https://doi.org/10.31117/neuroscirn.v1i3.22

21. Paudel YN, Lisgaras CP, Shaikh MF. Epilepsy and Comorbidities: Towards unraveling the common underlying mechanisms. Neurosci Res Notes. 2018;1(3):1-4. https://doi.org/10.31117/neuroscirn.v1i3.20

22. Mansor NI, Azmi N, Ling KH, Rosli R, Hassan Z, Nordin N. Prospective stem cell lines as in vitro neurodegenerative disease models for natural product research. Neurosci Res Notes. 2019;2(1):16-30. https://doi.org/10.31117/neuroscirn.v2i1.25

23. Leong MPY, Bala U, Lim CL, Rosli R, Cheah P-S, Ling KH. Transcriptomic profiling of skeletal muscle from the Ts1Cje mouse model of Down syndrome suggests dysregulation of trisomic genes associated with neuromuscular junction signaling, oxidative stress and chronic inflammation. Neurosci Res Notes. 2018, 1(1):21-41.

https://doi.org/10.31117/neuroscirn.v1i1.12

24. Bala U, Leong MP-Y, Lim CL, Shahar HK, Fauziah O, Cheah P-S. Ultrastructural study of sciatic nerve in Ts1Cje mouse model for Down syndrome: an implication of peripheral nerve defects in hypotonia. Neurosci Res Notes. 2018;1(2):1-9. https://doi.org/10.31117/neuroscirn.v1i2.17

25. Lim CL, Bala U, Leong MP-Y, Stanslas J, Ramasamy R, Ling K-H, et al. Cellular function of satellite cells does not play a role in muscle weakness of adult Ts1Cje mice. Neurosci Res Notes. 2018;1(1):3-10. https://doi.org/10.31117/neuroscirn.v1i1.6

26. Lutz J, Fiske A. Functional disability and suicidal behavior in middle-aged and older adults: A systematic critical review. $J$ Affect Disord. 2017;227(2):260-271. https://doi.org/10.1016/j.jad.2017.10.043

27. Tough H, Siegrist J, Fekete C. Social relationships, mental health and wellbeing in physical disability: a systematic review. BMC Public Health. 2017;17(1):414. https://doi.org/10.1186/s12889-017-4308-6

28. Skivington K, Matthews L, Craig P, Simpson S, Moore L. Developing and evaluating complex interventions: updating Medical Research Council guidance to take account of new methodological and theoretical approaches. Lancet. 2018;392:S2. https://doi.org/10.1016/s0140-6736(18)32865-4

29. Racine M. Chronic pain and suicide risk: A comprehensive review. Prog Neuropsychopharmacol Biol Psychiatry. 2017;87(Pt B):269-280. https://doi.org/10.1016/i.pnpbp.2017.08.020 